\title{
Polymeric Nanohydrogels of Poly(N-Isopropylacrylamide) Combined with Others Functionalized Monomers: Synthesis and Characterization
}

\author{
Lissette Agüero Luztonó ${ }^{1}$, Yuneivy Cepero Donates ${ }^{1}$, Luis Guillermo Guerrero Ramirez ${ }^{2}$, \\ Addys González Palomo ${ }^{3}$, Dionisio Zaldivar Silva ${ }^{1}$, Issa Katime ${ }^{2^{*}}$ \\ ${ }^{1}$ Departamento de Química Macromolecular, Centro de Biomateriales, Universidad de La Habana, Habana, Cuba; ${ }^{2}$ Grupo de Nuevos \\ Materiales y Espectroscopia Supramolecular, Facultad de Ciencias y Tecnología, Bilbao, España; ${ }^{3}$ Departamento de Biología de \\ Sistemas, Centro de Inmunología Molecular, Habana, Cuba. \\ Email: issa.katime@ehu.es
}

Received September $20^{\text {th }}$, 2013; revised December $15^{\text {th }}$, 2013; accepted January $3^{\text {rd }}, 2014$

Copyright (C 2014 Lissette Agüero Luztonó et al. This is an open access article distributed under the Creative Commons Attribution License, which permits unrestricted use, distribution, and reproduction in any medium, provided the original work is properly cited. In accordance of the Creative Commons Attribution License all Copyrights (C) 2014 are reserved for SCIRP and the owner of the intellectual property Lissette Agüero Luztonó et al. All Copyright (C) 2014 are guarded by law and by SCIRP as a guardian.

\section{ABSTRACT}

Nanohydrogels from inverse microemulsion (w/o) polymerization, at $25^{\circ} \mathrm{C}$, of $\mathrm{N}$-isopropylacrylamide (NIPA) and functionalized monomers are described. The functionalized monomers were: $\mathrm{N}$-(pyridine-4-ylmethyl) acrylamide (NP4MAM) and tert-butyl 2-acrylamidoethyl carbamate (2AAECM). The polymeric nanohydrogel obtained was characterized by attenuated total reflectance Fourier-transformed infrared spectroscopy (ATR-FTIR) and proton nuclear magnetic resonance spectrometry $\left({ }^{1} \mathrm{HNMR}\right)$, while their morphology and particle size was assessed by scanning electron microscopy (SEM) and dynamic light scattering. Their thermal properties were studied by Differential Scanning Calorimetry (DSC) and Thermogravimetric Analysis (TGA). As a preliminary measure of biocompatibility, in vitro evaluations of the nanohydrogels were carried out by cellular toxicity (colon carcinoma cells, CT-26) and hemocompatibility tests. These evaluations showed that these nanohydrogels were not toxic in the examined concentration range and exhibited preliminary blood compatibility; therefore they could be used in biomedical applications.

\section{KEYWORDS}

\section{N-Isopropylacrylamide; Nanohydrogels; Inverse Microemulsion Polymerization; In Vitro Biocompatibility}

\section{Introduction}

In the last years, synthetic hydrogels have attracted the attention of the scientific community since these polymers are capable of forming soft and porous three-dimensional scaffolds increasing their application in medicine and biotechnology [1-5]. In addition, the response to stimuli is a basic phenomenon in living system and human body is majority forming for soft tissues; therefore stimuli-sensitive hydrogels are promising materials as drug delivery systems [5-7].

Development of new polymeric materials as drug delivery system is necessary in order to improve therapies,

"Corresponding author. especially in cancer treatment, which involves utilization of many aggressive drugs with low therapeutic index causing adverse effects and poor acceptance from patients [8-10]. Stimuli-sensitive nanohydrogels containing bioactive specific ligands seem to be an effective strategy [11-15].

In this regard, many studies have been published utilizing poly (N-isopropylacrylamide) as a thermo-sensitive polymer due to its lower critical solution temperature (LCST) around $32^{\circ} \mathrm{C}$ in an aqueous solution. LCST is defined as the temperature when the polymer evolves from a hydrophilic (expanded structure) to a hydrophobic state (compact structure). This property can be manipulated to entrap drugs into polymer scaffolds and then re- 
lease them under the appropriate temperature conditions [16-21].

NP4MAM and 2AAECM are functionalized monomers synthesized in our laboratory in order to prepare multifunctional system [22]. Polymer containing pyridine moieties are interesting materials due to the presence of the nucleophilic nitrogen atom, which makes it possible to obtain $\mathrm{pH}$ sensitive polymers $[23,24]$. In this direction, we selected NP4MAM as a comonomer. Functionalization process can also provide reactive sites for postmodification reactions. Thus, the presence of carbamate group in 2AAECM plays a key role for attachment of other substances like enzymes, protein or peptides [25-27]. The combination of these monomers to produce multifunctional nanoarchitecture can significantly expand the scope of this system in drug delivery application.

In this work, we describe the synthesis and characterization of polymeric nanohydrogels with three different blocks: segments sensible to temperature (NIPA), segments sensible to $\mathrm{pH}$ (NPAMAM) and segments with carbamate pendant groups being amenable to subsequent introduction of a specific biochemical ligand (2AAECM). On the other hand, for a successful behavior of any device in the organism, biocompatibility is an essential requirement and that's why we performed in vitro biocompatibility tests by flow cytometry, FACS.

\section{Materials and Methods}

\subsection{Materials}

N-isopropylacrylamide (NIPA; Across Organic), N-(pyridine-4-ylmethyl) acrylamide (NP4MAM), tert-butyl 2acrylamidoethyl carbamate (2AAECM), acryloyl chloride (Aldrich), triethylamine (TEA, Merck), NN'-methylenebsiacrilamide (NMBA; Merck), $N$-tert-butoxycarbonyl-ethylendiamine (NHBOC), sorbitan sesquiolate (ARLACEL-83; Sigma Aldrich), polyoxythylene sorbitol hexaoleate (ATLAS G-1086; Sigma Aldrich), isoparaffinic oil (Isopar M, Esso Chemie), chloroform (Riedel de Haën), sodium metabisulfate $\left(\mathrm{Na}_{2} \mathrm{~S}_{2} \mathrm{O}_{5}\right.$, Merck), Milli Q water, diethyl ether (Panreac).

\subsection{Preparation of Nanoparticles by Inverse Microemulsion Polymerization}

Polymeric nanohydrogels were produced using water in oil system. The vinyl monomers: NIPA (10.44 g, 90 mol\%), NP4MAM (0.58 g, 5 mol\%), 2AAECM (0.58 g, $5 \mathrm{~mol} \%$ ) and NMBA as cross-linker (5 and $10 \mathrm{~mol} \%$ with respect to monomers amount) were dissolved in MilliQ water. For the oil phase, the appropriate amount of ATLAS G-1086 as surfactant and ARLACEL-83 as cosurfactant was dissolved in Isopar M. Previously, a phase diagram for ternary system oil-water-surfactant was constructed for selected experimental conditions. Under a nitrogen atmosphere, aqueous and oil phases were mixed in an IKA reactor equipped with mechanical stirrer and thermal sensor. Polymerization was initiated by the addition of sodium metabisulfate $(5 \mathrm{~mol} \%$ with respect to monomers amount) at $25^{\circ} \mathrm{C}$. The resultant product was purified several times by precipitation in excess amount diethyl ether and dried under vacuum. Slightly yellow power was obtained with a yield of $80 \%$.

\section{Characterization}

\subsection{FTIR Study}

The identification of functional groups present in polymeric nanohydrogels was carried out by Fourier transform infrared (FTIR) spectroscopy (Nicolet 6700, USA). The spectra were collected using an Attenuated Total Reflectance (ATR) smart orbit accessory within the scanning range $4000-400 \mathrm{~cm}^{-1}$.

\section{2. ${ }^{1}$ HNMR Study}

${ }^{1}$ HNMR spectra of polymeric nanohydrogels were recorded on a Bruker AEC instrument using deuterated water as solvent at 25,32 and $40^{\circ} \mathrm{C}(3000 \mathrm{~Hz})$. The chemical shifts were recorded in parts per million (ppm) using tetramethylsilane (TMS, $0.00 \mathrm{ppm}$ ) as internal reference.

\subsection{Thermogravimetric Analysis}

Thermogravimetric analyses (TGA) was carried out on a SDT $600 \mathrm{TA}$ instrument at a heating rate of $10^{\circ} \mathrm{C} / \mathrm{min}$ under nitrogen flow $(100 \mathrm{~mL} / \mathrm{min})$. Differential scanning calorimetry (DSC) measurements were conducted on a DSC 2920 TA instrument from 10 to $200^{\circ} \mathrm{C}$ at a heating rate of $10^{\circ} \mathrm{C} / \mathrm{min}$ under nitrogen atmosphere.

\subsection{Morphology}

Scanning electron microscopy (SEM) measurements were performed on JEOL $7000 \mathrm{~F}$ equipment at $10 \mathrm{kV}$. Samples were prepared by dropping of diluted nanohydrogel solutions on microscope glass plate and dried in air at room temperature for $24 \mathrm{~h}$. The dried samples were sputtered with thin gold/palladium layer prior to observation.

\subsection{Size Particle}

Dynamic laser light scattering measurements for determining the size of the gels were performed using a Brookhaven BI-9000AT goniometer. A water-cooled argon-ion laser was operated at $514.5 \mathrm{~nm}$ as the light source. The time dependence of the intensity autocorrela- 
Functionalized Monomers: Synthesis and Characterization

tion function of the scattered intensity was obtained by using a 522-channel digital correlator. The size of the nanoparticles was determined from the diffusion intensity of the particles using the Stokes-Einstein equation. The size distributions were obtained by CONTIN analysis. The dried powder samples were dispersed in water (1 $\mathrm{mg} \cdot \mathrm{mL}^{-1}$ ) during $24 \mathrm{~h}$. All the measurements were carried out at $25^{\circ} \mathrm{C}$.

\subsection{Cytotoxicity Assay}

Cytotoxicity study of the nanohydrogels was carried out by culturing murine colon carcinoma cells (CT26, ATCC). CT26 cells were cultured in a Dulbecco's modified Eagle's medium (DMEM) supplemented with 5\% of foetal calf serum (FCS), 1\% penicillin/streptomycin at $37^{\circ} \mathrm{C}$ in a humidified atmosphere containing $5 \% \mathrm{CO}_{2}$. CT-26 cells were seeded on 24-well plates at a density of $1.0 \times 10^{5}$ cells per well and incubated for 2 days until cells reached confluence. Polymeric nanohydrogels were previously dispersed in a phosphate buffered saline (PBS 1X) (1 mg of nanohydrogels/mL of PBS $1 \mathrm{X}$ ) and added to confluents cells at a final concentration of 50, 100 and $500 \mu \mathrm{g} / \mathrm{mL}$ for 24 and 48 hours. Phenol 1\% was used as positive control (i.e., caused death). After incubation time, cells were washed with PBS 1X and labeled with propidium iodide (PI) at $10 \mu \mathrm{g} / \mathrm{mL}$. The effect of different treatments on cell toxicity was assessed by flow cytometry assay (FACS can instrument, BD Biosciences, equiped with $488 \mathrm{~nm}$ argon laser). Each experiment was performed in triplicate and cytotoxicity was expressed as the percentage of PI-positive cells.

\subsection{Hemocompatibility Test}

In vitro hemolysis test was performed with blood from nife C57BL/6 mice. Whole blood was collected using EDTA. $50 \mu \mathrm{L}$ of blood diluted with $500 \mu \mathrm{L}$ of PBS (pH = 7.4) and $500 \mu \mathrm{L}$ of distilled water were taken as negative ( $0 \%$ hemolysis) and positive (100\% hemolysis) controls, respectively. In a similar manner, to obtain a control graph of hemolysis, $50 \mu \mathrm{L}$ of blood was diluted with different amounts of PBS and water (v/v): 9:1, 8:2, 7.3, 6:4, 1:1, 4:6, 3:7, 2:8 and 1:9. Then $1 \mathrm{mg}$ of polymeric nanohydrogels were placed in a tube containing $50 \mu \mathrm{L}$ of blood (diluted with $500 \mu \mathrm{L}$ of PBS 1X). The contents of all the tubes were gently mixed and incubated in a water bath at $37^{\circ} \mathrm{C}$ for 1 hour. Subsequently, all tubes were centrifuged at 14,000 rpm for 5 min and the supernant was taken for the estimation of free hemoglobin. Absorbance was recorded at $540 \mathrm{~nm}$ and the percentage of hemolysis after nanohydrogels incubation was estimated from the standard calibration curve. Additionally \% hemolysis of the positive and negative controls at different times was measured.

\subsection{Statistical Analysis}

Experiments were carried out at least in triplicate, and comparison of mean values was performed using nonparametric one-way analyses of variance (ANOVA) and Kruskal-Wallis test. Differences with $p<0.05$ were considered statically significant.

\section{Results and Discussion}

\subsection{Synthesis}

Poly(N-isopropylacrylamide-co-N-(pyridine-4-ylmethyl) acrylamide-co-tert-butyl 2-acrylamidoethyl carbamate) nanohydrogels,

[Poly(NIPA-co-NP4MAM-co-2AAECM)], were synthesized through inverse microemulsion polymerization as shown in Figure 1. Functionalized monomers were previously synthesized by reacting acryloyl chloride with 4 amino-methyl pyridine and NHBOC in the presence of TEA at $-20^{\circ} \mathrm{C}$. Detailed information of their synthesis has been published previously [22].

\subsection{FTIR Characterization}

The FTIR spectra of polymeric nanohydrogels are shown in Figure 2. The spectra exhibit characteristic absorption peaks at $1636 \mathrm{~cm}^{-1}(\mathrm{C}=\mathrm{O}$ stretching, amide $\mathrm{I})$ and 1535 $\mathrm{cm}^{-1}$ (N-H bending, amide II) attributed to secondary amide groups present in all monomers. Absorption at $1457 \mathrm{~cm}^{-1}$ has been identified as $\mathrm{C}=\mathrm{C}$ stretching vibration in the pyridine ring, NP4MAM segments. The peaks at 2970, 2929 and $2872 \mathrm{~cm}^{-1}$ are due to $\mathrm{CH}, \mathrm{CH}_{2}, \mathrm{CH}_{3}$ symmetric and asymmetric stretching. In addition, absorption bands at 1386 and $1366 \mathrm{~cm}^{-1}$ correspond to the isopropyl and tert-butyl groups present in PNIPA and 2AAECM segments, respectively. A typical absorption peak at $3280 \mathrm{~cm}^{-1}$ was assigned to N-H stretching of the secondary amide group, while the peak at $3070 \mathrm{~cm}^{-1}$ is due to aromatic $=\mathrm{CH}$ stretching in the pyridine ring. $\mathrm{Fi}-$ nally, a band for the COC symmetric stretching vibration appears in the region of $1171-1129 \mathrm{~cm}^{-1}$ corresponding to 2AAECM segments. We found that the FTIR spectra for polymeric nanohydrogels with two different compositions (5\% and $10 \%$ of NMBA) are similar.

\section{3. ${ }^{1}$ HNMR Study}

The ${ }^{1}$ HNMR spectrum and chemical shift assignments of synthesized polymeric nanohydrogels were presented in Figure 3, using one of them with a composition of $10 \%$ NMBA as example. The characteristic peaks pertaining to PNIPA were found at $1.12 \mathrm{ppm}\left(\mathrm{CH}_{3}\right.$, signal $\left.d\right), 1.56$ 


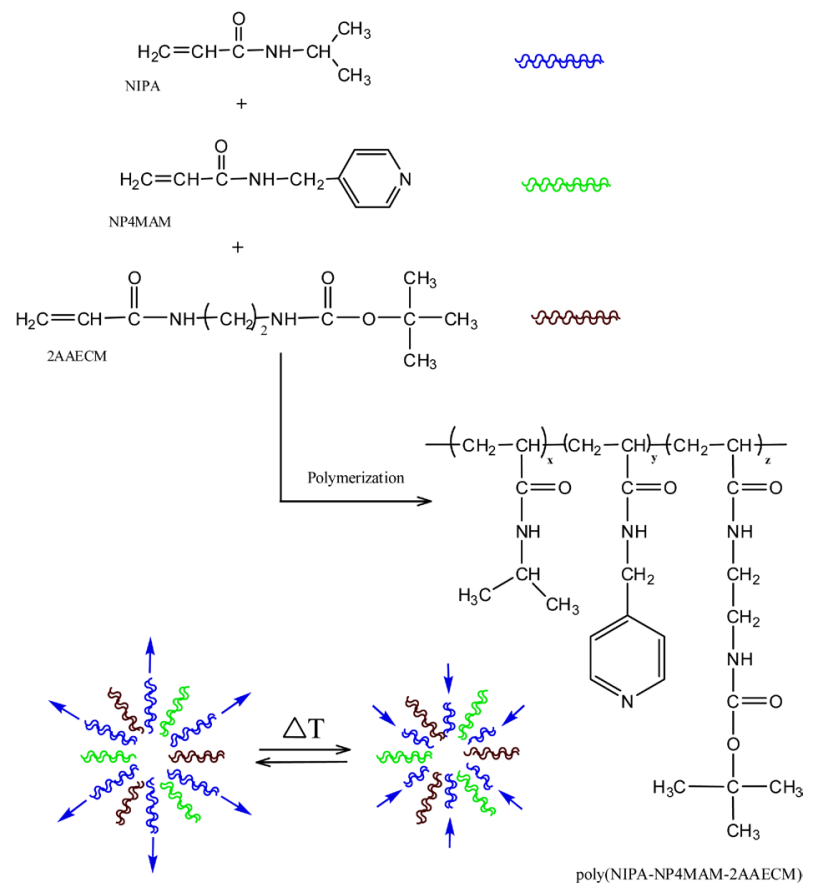

Figure 1. Scheme of polymerization of poly(NIPA-co-NP4MAM-co-2AAECM) nanohydrogels.

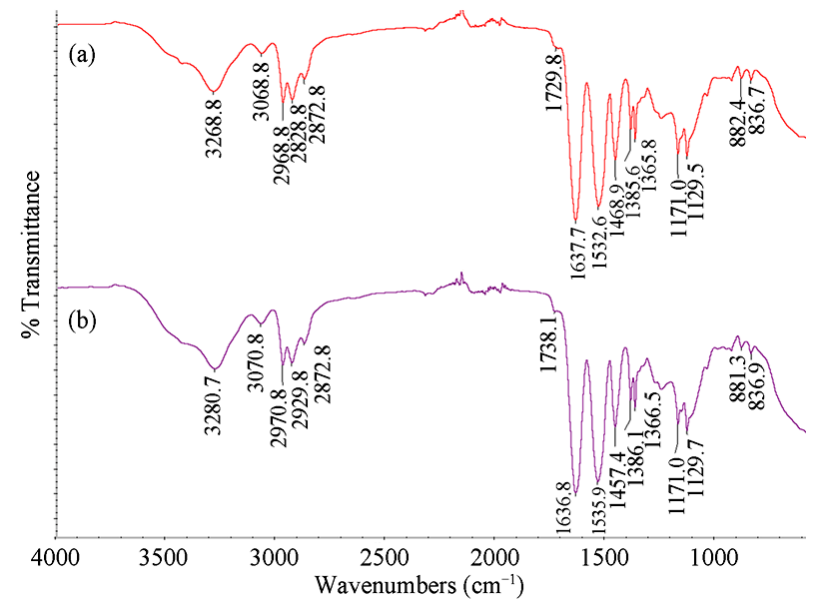

Figure 2. FTIR spectra of poly (NIPA-co-NP4MAM-co2AAECM) nanohydrogels: (a) 5\% NMBA, (b) $10 \%$ NMBA.

ppm (CH, signal $a)$, $1.98 \mathrm{ppm}\left(\mathrm{CH}_{2}\right.$, signal $\left.b\right)$ and 3.87 ppm $(\mathrm{CH}$, signal $c)$. The signal peaks of 2AAECM can be observed at $1.41 \mathrm{ppm}\left(\mathrm{CH}_{3}\right.$, signal $\left.i\right)$ and $3.69 \mathrm{ppm}$ $\left(\mathrm{CH}_{2}\right.$, signal $\left.h\right)$. The pyridine ring peaks were observed at 7.76 and $8.68 \mathrm{ppm}$ (signal $f$ and signal $g$ ), while those at $4.39 \mathrm{ppm}$ are assigned to $\mathrm{CH}_{2}$ (signal e). NMR spectra confirm the formation of the nanohydrogels in good agreement with FTIR measurements.

It can be expected that the synthesized Poly(NIPAco-NP4MAM-co-2AAECM) also exhibit therrmosensible response as PNIPA and the formation of the new chemical structure does not affect this behavior. In

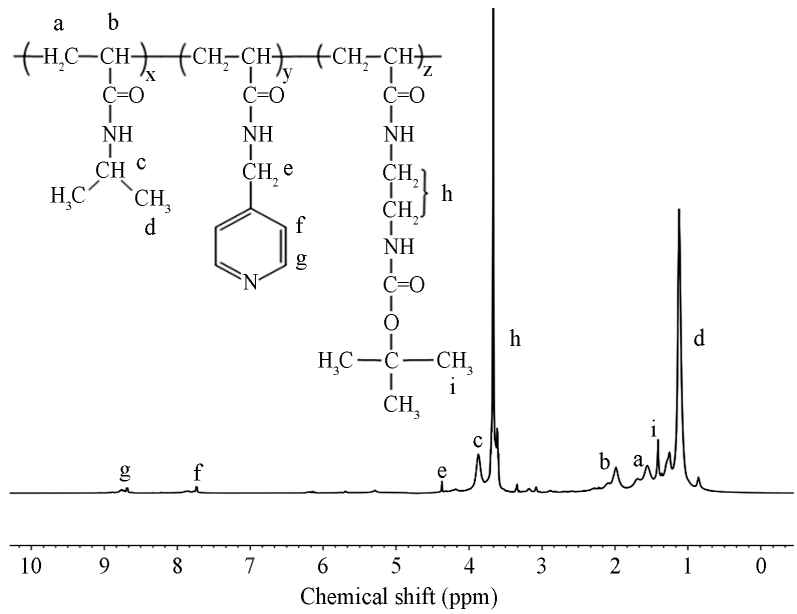

Figure 3. ${ }^{1} \mathrm{HNMR}$ spectra of the polymeric nanohydrogels with $10 \%$ of NMBA in deuterated water $\left(\mathrm{D}_{2} \mathrm{O}\right)$ at $25^{\circ} \mathrm{C}$.

${ }^{1}$ HNMR spectra recorded at different temperature we can observe that signal intensities, corresponding to PNIPA segments, decrease considerably at 32 , and at $40^{\circ} \mathrm{C}$ could hardly be detected (Figure 4). When the solution of nanohydrogels is heated PNIPA chains are dehydrated and collapsed as a water-insoluble compact form, therefore PNIPA units cannot be detected easily at high temperature.

\subsection{Morphology and Size Particle}

Scanning electron microscopy was utilized to evaluate only morphology of the resulting Poly(NIPA-co-NP4MA $\mathrm{M}$-co-2AAECM) as a function of crosslinker concentration (Figure 5). The nanohydrogel dispersed in water show spherical morphology but some aggregates are observed in the micrograph. The presence of pyridine and amide side chains in the polymer structure contributes to its hydrophilic behavior due to their affinity with water molecules through hydrogen bond formation, leading some aggregation of nanoparticles.

The most important feature of nanoparticles is their small size. Thus, the size of the polymeric nanohydrogels was measured by dynamic light scattering as $166 \pm 4$ and $142 \pm 3 \mathrm{~nm}$ for 5 and $10 \%$ of NMBA, respectively. Effect of different parameters of size particle will report in next manuscript.

\subsection{Thermogravimetric Analysis}

Thermal properties of poly(NIPA-co-NP4MAM-co-2AA ECM) nanohydrogels were studied by TGA-DTGA and DSC analysis. The TGA weight loss vs. temperature plot for two compositions of nanohydrogels is illustrated in Figure 6 and summarized in Table 1. It is clear that the weight loss curve of nanohydrogels is almost the same and shows a major single stage in the temperature range 

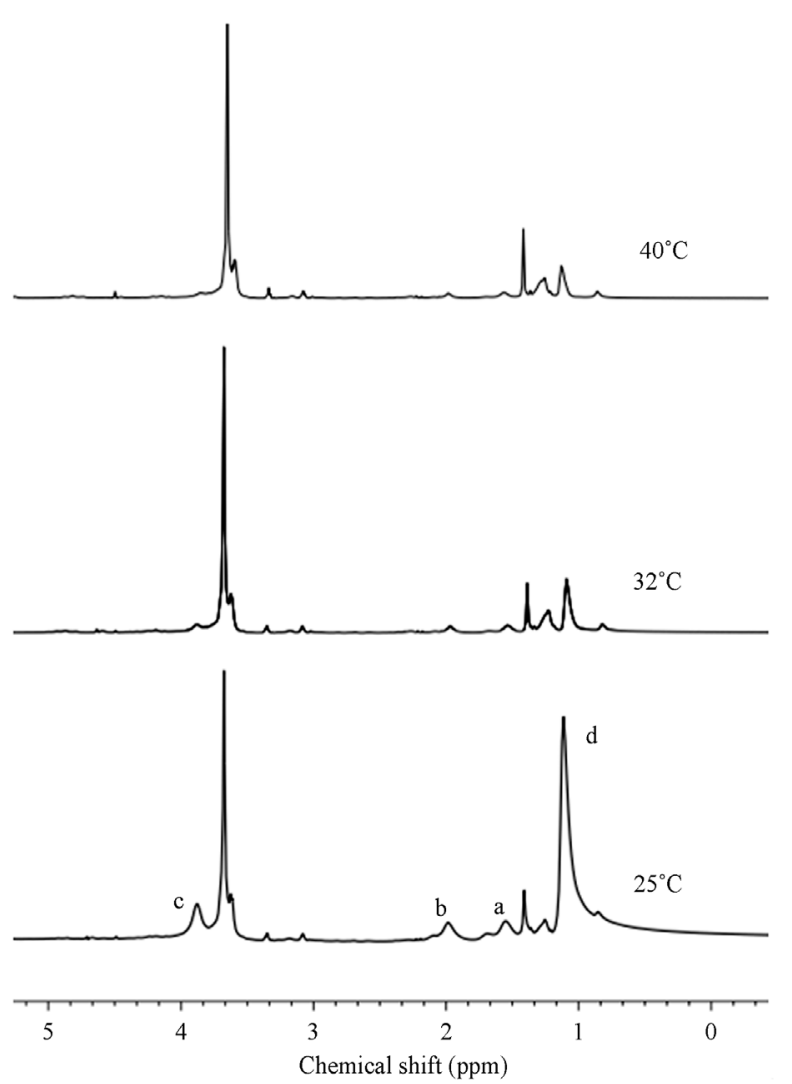

Figure 4. ${ }^{1}$ HNMR spectra of the polymeric nanohydrogels with $10 \%$ of NMBA recorded at different temperature in deuterated water $\left(\mathrm{D}_{2} \mathrm{O}\right)$.

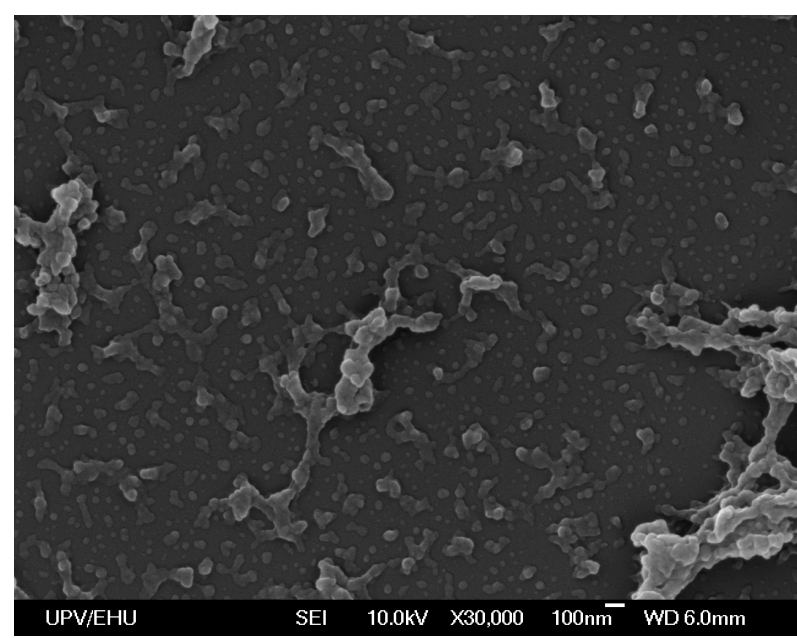

Figure 5. SEM images of $\mathbf{1 0} \%$ crosslinking Poly(NIPA-coNP4MAM-co-2AAECM) nanohydrogels. The scale bar is $100 \mathrm{~nm}$.

$230-465^{\circ} \mathrm{C}$, indicating of the terpolymer produced is thermally stable. This thermal event is related to total decomposition of side groups due to cleavage of the polymer backbone.

The results obtained by DSC analysis are illustrated in
Figure 7 , using a hydrogel with $10 \%$ of NMBA as example. The glass transition temperature $\left(T_{g}\right)$ for both compositions are reported in Table 1 and their value was taken as a midpoint inflection. Increase crosslinking density in the reaction mixture generate a rigid structure leading to a $\mathrm{T}_{\mathrm{g}}$ value increase, but in agreement with previous results, no significant variations are observed when the percentage of NMBA within the nanohydrogels is increased.

Table 1. Thermal behavior of poly(NIPA-co-NP4MAM-co2AAECM) nanohydrogels.

\begin{tabular}{cccc}
\hline & TGA & DTGA & DSC \\
\hline Samples & Loss weight $(\%)$ & $\mathrm{T}_{\mathrm{d}}\left({ }^{\circ} \mathrm{C}\right)$ & $\mathrm{Tg}\left({ }^{\circ} \mathrm{C}\right)$ \\
$5 \%$ NMBA & 88.2 & 395.7 & 60.3 \\
$10 \%$ NMBA & 88.0 & 397.3 & 62.9 \\
\hline
\end{tabular}

$\mathrm{T}_{\mathrm{d}}$ value corresponds to peak maximum decomposition.

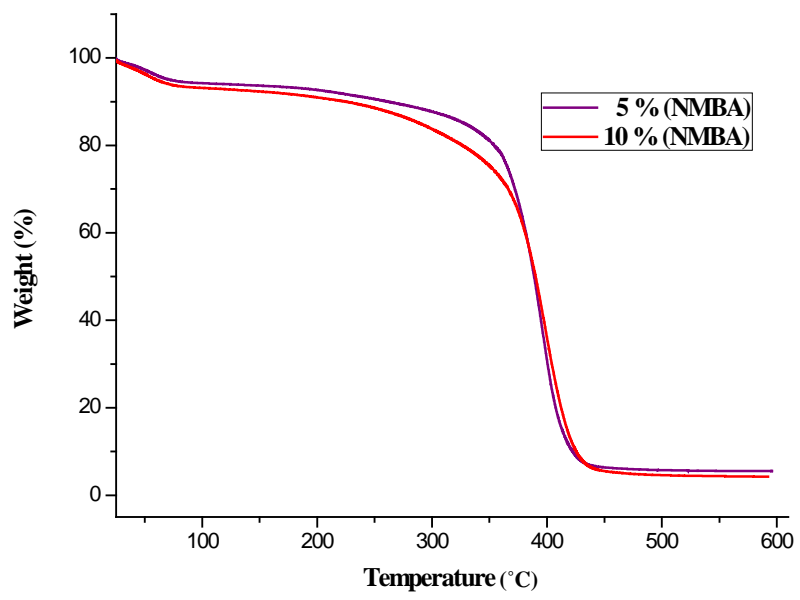

Figure 6. TGA weight loss curves for poly(NIPA-NP4MAM-2AAECM) nanohydrogels.

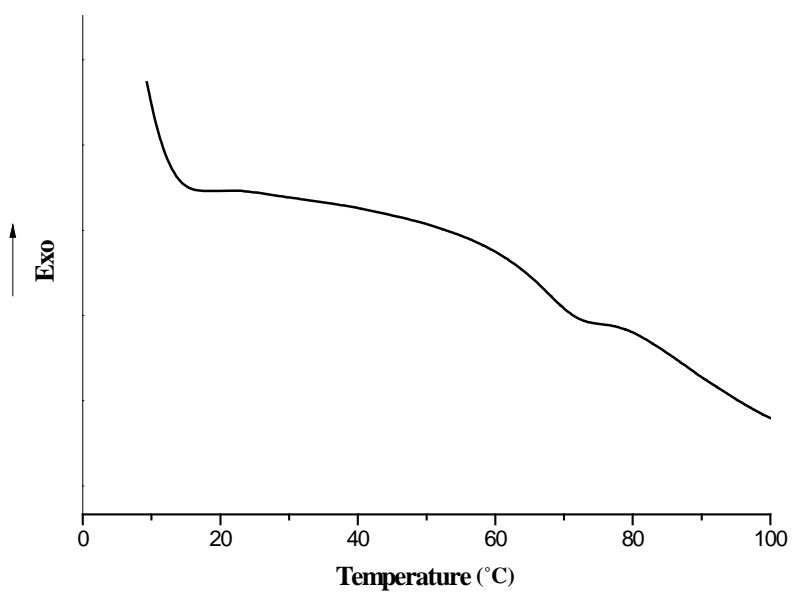

Figure 7. DSC curves of poly(NIPA-co-NP4MAM-co-2AAECM) nanohydrogels with $10 \%$ of NMBA. 


\subsection{Cytotoxicity of Polymeric Nanohydrogels in CT 26 Cells}

Good biocompatibility is an important criterion for selection of materials to be introduced in organism. Taking in consideration of some studies indicate that nanoparticles may cause adverse effects due to their small size, evaluation of cytotoxicity is an important step in early preclinical evaluation $[28,29]$. Taking into account that nanoparticles will be use as delivery system, including chemotherapeutics drugs, we select the CT-26 cells.

Figures 8(a) and (b) show the representative histogram of CT26 cells treated with the higher concentration of nanohydrogels ( $500 \mu \mathrm{g} / \mathrm{mL})$, at 24 and $48 \mathrm{~h}$, respectively. Here, death of CT-26 cells in presence of $1 \%$ phenol (positive control) was about $47 \%$ at $24 \mathrm{~h}$. At the same time, the induction of toxicity in CT-26 cells treated with various concentrations of nanohydrogels (50, 100 and $500 \mu \mathrm{g} / \mathrm{mL}$ ) was minor than $10 \%$, Figures 8(a) and (c). The toxicity of nanoparticles over tumor cells was not increased at $48 \mathrm{~h}$; however, the positive control was increased at 60\%, Figures 8(b) and (d). Additionally, two compositions of nanoparticles (5\% and $10 \%$ NMBA) showed comparable citotoxicity at 24 and $48 \mathrm{~h}$.

Statistical analysis corroborate that cells with or without treatments show similar percent of citotoxicity at both times $(p<0.05)$, Figures 8(c) and (d). There were also no differences among citotoxicity by exposition time (24 to $48 \mathrm{~h}$ ).
In vitro toxicity assessment has become widely used for recent toxicity studies. Such assays provide rapid, cost effective and reliable results. Toxicity results of nanohydrogels in murine colon carcinoma cells indicate that nanoparticles at concentrations used in the present study were no toxic.

\subsection{Hemocompatibility Test}

Hemolysis, in vivo, can lead to anemia, jaundice and other pathological conditions. Nanoparticles are emerging as drug carriers [8]. Their small size and unique physicochemical properties may cause interactions with erythrocytes [30]. For that reason, determination of hemolytic properties is one of the most common tests to evaluate, their biocompatibility with blood components.

The calibration curve shows the increase of the absorbance (hemolysis) by increase water in solvent. This indicate that enhance of eritrocytes lysis is due to the decrease of solvent osmolarity (Figure 9(a)).

We analyze the effect of two different compositions of nanohydrogels (5\% and 10\% NMBA) on blood samples. The absorbance obtained after $1 \mathrm{~h}$ incubation of hydrogels in blood, at all concentrations tested, was similar to the mean absorbance value obtained for blood diluted with PBS $1 \mathrm{X}$ (0\% hemolysis control) (Figure 9(b)). A low percentage hemolysis was estimated with both formulations and it appeared to have no relationship to the concentration of nanoparticles (less than $1 \%$ hemolysis). This result sug-
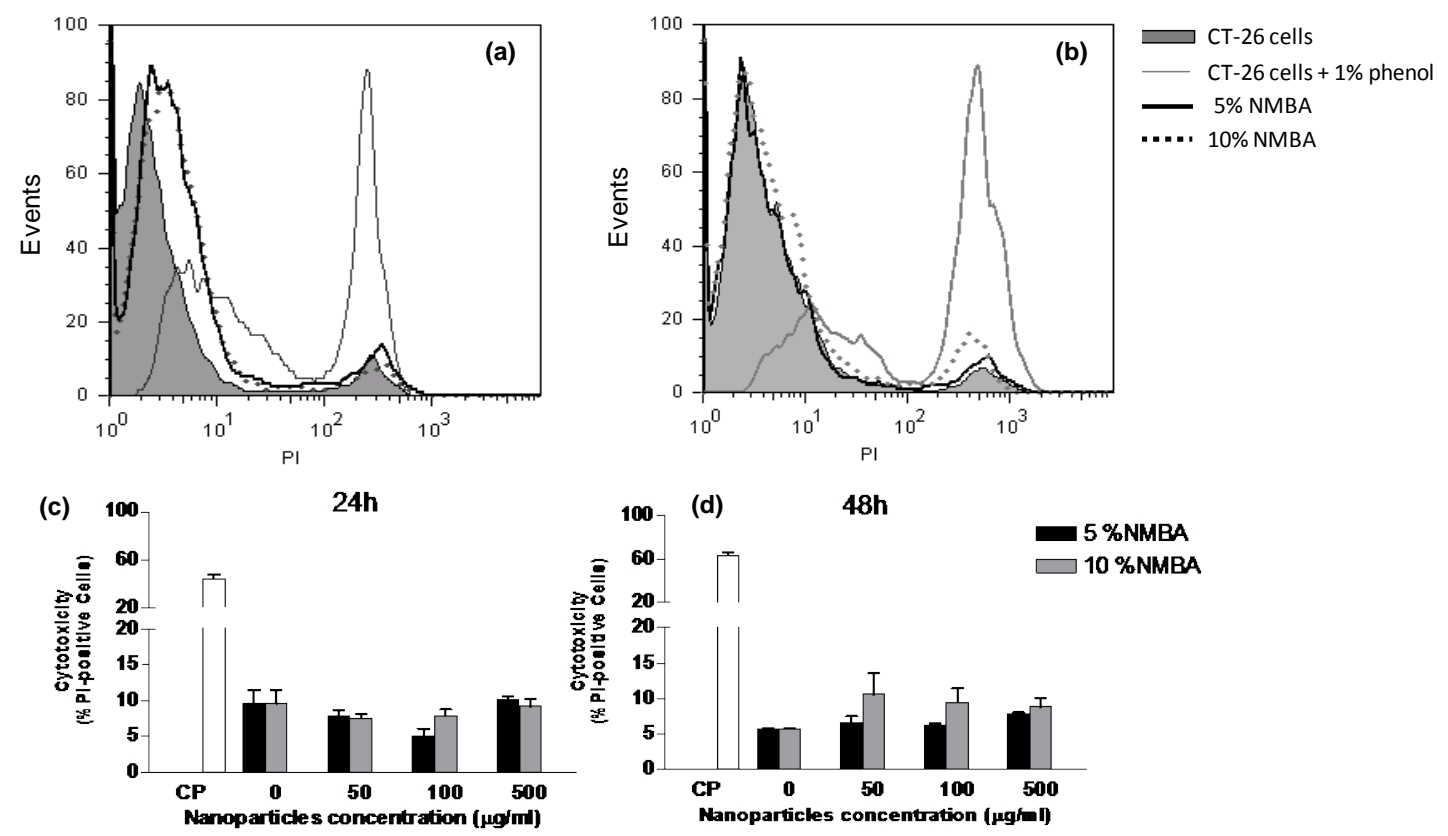

Figure 8. Citotoxicity assay of CT-26 cells treated with nanohydrogels of 5\% and 10\% NMBA. (a) (24 h) and (b) (48 h): CT 26 cells treated with $500 \mu \mathrm{g} / \mathrm{mL}$ nanohydrogels with 5\% (black line) and 10\% NMBA (dashed line). Negative control (cells without treatment, gray histogram). Positive control (cells with phenol 1\%, gray line). (c) and (d): CT-26 cells were treated with nanoparticles at 50, 100 and $500 \mu \mathrm{g} / \mathrm{mL} .0 \mu \mathrm{g} / \mathrm{mL}$ (negative control); CP: positive control. 


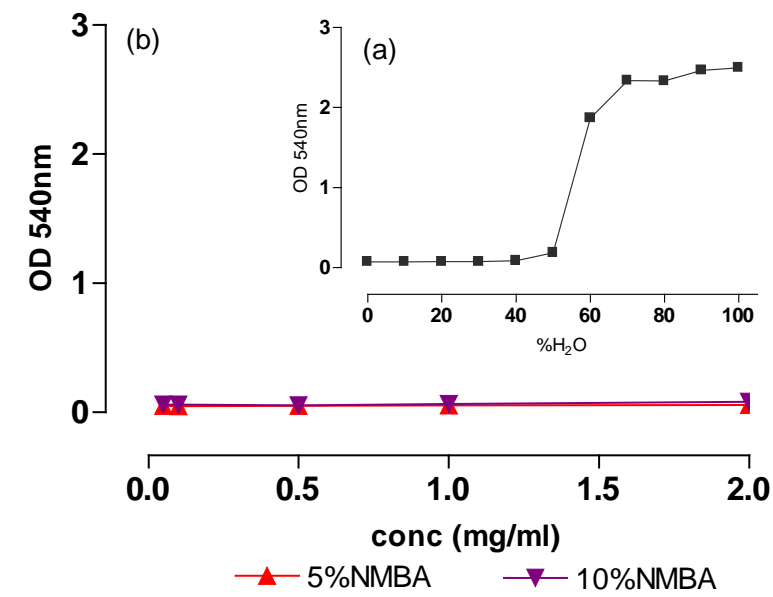

Figure 9. Effect of nanohydrogels of $5 \%$ and $10 \%$ NMBA in hemolysis. (a) Calibration curve of eritrocytes lysis at different proportions water/PBS1x, (v/v); (b) Quantification of free hemoglobin in blood samples treated with nanohydrogels at different concentrations.

gests that nanohydrogels not induce hemolysis and may be used in the future for drug delivery application.

\section{Conclusion}

In summary, Poly(NIPA-co-NP4MAM-co-2AAECM) nanohydrogels were synthesized with special architectures by inverse microemulsion polymerization using sodium metabisulfate as initiation system. Multifunctional nanohydrogels were prepared incorporating NP4MAM and 2AAECM as comonomers. However, we only evaluated the thermosensitive response by ${ }^{1}$ HNMR in this report. The properties of nanohydrogels were examined by FTIR, SEM, DSC, and TGA. SEM micrographs show spherical nanoparticles and evidenced the hydrophilic character of our system through slight aggregation process. The data obtained in each experiment demonstrated that the size particle, morphology and thermal properties did not experience significant changes with increase in the degree of crosslinking. Therefore we will concentrate in samples with $5 \%$ of NMBA in future works. In addition, good results obtained in the cytotoxicity and hemocompatibilty tests suggest that poly(NIPA-co-NP4MAM-co-2AA-ECM) nanohydrogels have potential as biomaterial for biomedical applications.

\section{Acknowledgements}

Financial support for this work from Ministerio de Ciencia y Tecnología is gratefully acknowledged (MICINN). L. Agüero acknowledges the award of a fellowship from the MAEC-AECID during 2008-2009. We would like to thanks Dr. Kaleb León Monzón for his help with cell culture experiments.

\section{REFERENCES}

[1] S. Chaterji, I. K. Kown and K. Park, "Smart Polymeric Gels: Redefining the Limits of Biomedical Devices," Progress in Polymer Science, Vol. 32, No. 8-9, 2007, pp. 1083-1122.

http://dx.doi.org/10.1016/j.progpolymsci.2007.05.018

[2] J. Kopeĉek and J. Yang, "Hydrogels as Smart Biomaterials,” Polymer International, Vol. 56, No. 9, 2007, pp. 1078-1098. http://dx.doi.org/10.1002/pi.2253

[3] N. A. Peppas, P. Bures, W. Leobandung and H. Ichikawa, "Hydrogels in Pharmaceutical Formulations," European Journal of Pharmaceutics and Biopharmaceutics, Vol. 50, No. 1, 2000, pp. 27-46.

http://dx.doi.org/10.1016/S0939-6411(00)00090-4

[4] L. G. Guerrero-Ramírez, S. M. Nuño-Donlucas, L. C. Cesteros and I. Katime, "Smart Copolymeric Nanohydrogels: Synthesis, Characterization and Properties," Materials Chemistry and Physics, Vol. 112, No. 3, 2008, pp. 10881092.

[5] S. Dinçer, Z. M. O. Rzaev and E. Pişkin, "Synthesis and Characterization of Stimuli-Responsive Poly(N-Isopropy-lacrylamideco-N-Vinyl-2-Pyrrolidone)" Journal of Polymer Research, Vol. 13, No. 2, 2006, pp. 121-131. http://dx.doi.org/10.1007/s10965-005-9014-x

[6] B. V. Slaughter, S. S. Khurshid, O. Z. Fisher, A. Khademihosseini and N. A. Peppas, "Hydrogels in Regenerative Medicine," Advanced Materials, Vol. 21, No. 32-33, 2009, pp. 3307-3329. http://dx.doi.org/10.1002/adma.200802106

[7] L. Péres, V. Sáez and I. Katime, "Novel pH and Temperature Responsive Methacrylamide Microgels," Macromolecular Chemistry \& Physics, Vol. 210, No. 13-14, 2009, pp. 1120-1126

[8] N. P. Praetorius and T. K. Mandal, "Engineered Nanoparticles in Cancer Therapy," Recent Patent on Drug Delivery \& Formulation, Vol. 1, No. 1, 2007, pp. 37-51. http://dx.doi.org/10.2174/187221107779814104

[9] J. D. Kingsley, H. Dou, J. Morehead, B. Rabinow, H. E. Gendelman and C. J. Destache, "Nanotechnology: A Focus on Nanoparticles as a Drug Delivery System," Journal of Neuroimmune Pharmacology, Vol. 1, No. 3, 2006, pp. 340-350.

http://dx.doi.org/10.1007/s11481-006-9032-4

[10] E. S. Gil and S. M. Hudson, "Stimuli-Reponsive Polymers and Their Bioconjugates," Progress in Polymer Science, Vol. 29, No. 12, 2004, pp. 1173-1222. http://dx.doi.org/10.1016/j.progpolymsci.2004.08.003

[11] N. Singh and L. A. Lyon, "Synthesis of Multifunctional Nanogels Using a Protected Macromonomer Approach,” Colloid and Polymer Science, Vol. 286, No. 8-9, 2008, pp. 1061-1069. http://dx.doi.org/10.1007/s00396-008-1883-1

[12] S. Shidhaye, V. Lotlikar, S. Malke and V. Kadam, "Nanogel Engineered Polymeric Micelles for Drug Delivery,” Current Drug Therapy, Vol. 3, No. 3, 2008, pp. 209-217.

[13] M. Ferrari, "Cancer Nanotechnology: Opportunities and Challenges,” Nature Review, Vol. 5, No. 3, 2005, pp. 161-171. http://dx.doi.org/10.1038/nrc1566 
[14] D. P. Chang, J. E. Dolbow and S. Zauscher, "Switchable Friction of Stimulus-Responsive Hydrogels” Langmuir, Vol. 23, No. 1, 2007, pp. 250-257. http://dx.doi.org/10.1021/la0617006

[15] N. Morimoto, X.-P. Qiu, F. M. Winnik and K. Akiyoshi, "Dual Stimuli-Responsive Nanogels by Self-Assembly of Polysaccharides Lightly Grafted with Thiol-Terminated Poly(N-isopropylacrylamide) Chains," Macromolecules, Vol. 41, No. 16, 2008, pp. 5985-5987. http://dx.doi.org/10.1021/ma801332x

[16] X. Jiang, J. Zhang, Y. Xhou, J. Xu and S. Liu, "Facile Preparation of Core-Crosslinked Micelles from AzideContaining Thermoresponsive Double Hydrophilic Diblock Copolymer via Click Chemistry,” Journal of Polymer Science Part A: Polymer Chemistry, Vol. 46, No. 3, 2008, pp. 860-871. http://dx.doi.org/10.1002/pola.22430

[17] Y. Z. You, K. K. Kalebaila, S. L. Brock and D. Oupický, "Temperature-Controlled Uptake and Release in PNIPAM-Modified Porous Silica Nanoparticles,” Chemistry of Materials, Vol. 20, No. 10, 2008, pp. 3354-3359. http://dx.doi.org/10.1021/cm703363w

[18] A. S. Mathews, C.-S. Ha, W.-J. Cho and I. Kim, "Drug Delivery System Based on Covalently Bonded Poly[NIsopropylacrylamide-co-2-Hydroxyethylacrylate]-Based Nanoparticle Networks,” Drug Delivery, Vol. 13, No. 4, 2006, pp. 245-251. http://dx.doi.org/10.1080/10717540500313067

[19] J. Zhang, H. Chen, L. Xu and Y. Gu, "The Targeted Behavior of Thermally Responsive Nanohydrogel Evaluated by NIR System in Mouse Model," Journal of Controlled Release, Vol. 131, No. 1, 2008, pp. 34-40. http://dx.doi.org/10.1016/j.jconrel.2008.07.019

[20] N. Singh and L. Andrew, "Synthesis of Multifunctional Nanogels Using a Protected Macromonomer Approach," Colloid \& Polymer Science, Vol. 286, No. 8-9, 2008, pp. 1061-1069. http://dx.doi.org/10.1007/s00396-008-1883-1

[21] A. Uzgören, Z. M. O. Rzaev and G. Okay, "Bioengineering Functional Copolymers: Synthesis and Characterization of Poly(N-Isopropyl Acrylamide-co-3,4-2H-Dihydropyran)s," Journal of Polymer Research, Vol. 14, No. 4, 2007, pp. 329-338. http://dx.doi.org/10.1007/s10965-007-9116-8
[22] L. Agüero, G. Guerrero-Ramírez and I. Katime, "New Family of Functionalized Monomers Based on Amines: A Novel Synthesis That Exploits the Nucleophilic Substitution Reaction,” Journal of Materials Science and Applications, Vol. 1, 2010, pp. 103-108. http://dx.doi.org/10.4236/msa.2010.13018

[23] H. Namazi and M. Adeli, "Dendrimers of Citric Acid and Poly (Ethylene Glycol) as the New Drug-Delivery Agents," Biomaterials, Vol. 26, No. 10, 2005, pp. 1175-1183. http://dx.doi.org/10.1016/j.biomaterials.2004.04.014

[24] E. A. Papageorgiu, M. J. Gaunt, J. Yu and J. B. Spencer, "Selective Hydrogenolysis of Novel Benzyl Carbamate Protecting Groups,” Organic Letters, Vol. 2, No. 8, 2000, pp. 1049-1051. http://dx.doi.org/10.1021/ol0055891

[25] R. B. Greenwald, Y. H. Choe, C. D. Conover, K. Shum, D. Wu and M. Royzen, "Drug Delivery Systems Based on Trimethyl Lock Lactonization: Poly(Ethylene Glycol) Prodrugs of Amino-Containing Compounds," Journal of Medicinal Chemistry, Vol. 43, No. 3, 2000, pp. 475-487. http://dx.doi.org/10.1021/jm990498j

[26] E. R. Beckel, J. W. Stansbury and C. N. Bowman, "Effect of Aliphatic Spacer Substitution on the Reactivity of Phenyl Carbamate Acrylate Monomers," Macromolecules, Vol. 38, No. 8, 2005, pp. 3093-3098. http://dx.doi.org/10.1021/ma048359l

[27] D. Noda, M. Yasutake, H. Takemura and T. Shinmyozu, "Synthesis of a New Pyridinophane Macrocycle with Carbamate Functionality via Novel $\mathrm{CO}_{2}$ Insertion Reaction," Tetrahedron Letters, Vol. 40, No. 17, 1999, pp. 33473350. http://dx.doi.org/10.1016/S0040-4039(99)00512-2

[28] P. H. M. Hoet, I. Brüske-Hohlfed and O. V. Salata, "Nanoparticles-Known and Unknown Health Risks,” Journal of Nanotechnology, Vol. 2, No. 12, 2004, pp. 2-15.

[29] W. H. De Jong and P. J. A. Borm, "Drug Delivery and Nanoparticles: Applications and Hazards,” International Journal of Nanomedicine, Vol. 3, No. 2, 2008, pp. 133149. http://dx.doi.org/10.2147/IJN.S596

[30] M. A. Dobrovolskaia, J. D. Clogston, B. W. Neun, J. B. Hall, A. K. Patri and S. E. McNeil, "Method for Analysis of Nanoparticle Hemolytic Properties in Vitro," Nano Letters, Vol. 8, No. 8, 2008, pp. 2180-2187. http://dx.doi.org/10.1021/nl0805615 